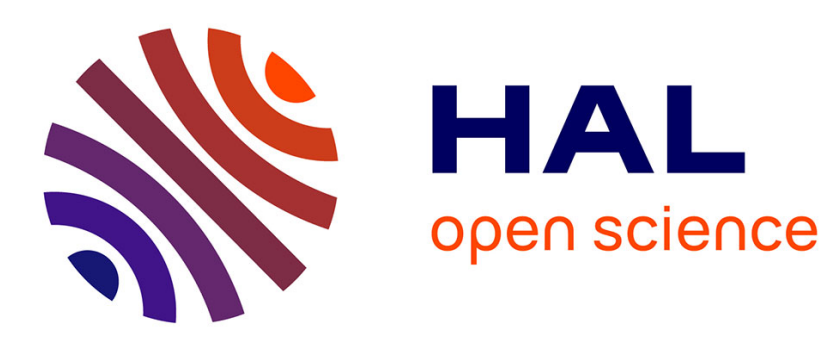

\title{
Global Capitalism and the Critique of Real Time
}

Wayne Hope

\section{To cite this version:}

Wayne Hope. Global Capitalism and the Critique of Real Time. Time \& Society, 2006, 15 (2-3), pp.275-302. 10.1177/0961463X06066943 . hal-00571012

\section{HAL Id: hal-00571012 https://hal.science/hal-00571012}

Submitted on 1 Mar 2011

HAL is a multi-disciplinary open access archive for the deposit and dissemination of scientific research documents, whether they are published or not. The documents may come from teaching and research institutions in France or abroad, or from public or private research centers.
L'archive ouverte pluridisciplinaire HAL, est destinée au dépôt et à la diffusion de documents scientifiques de niveau recherche, publiés ou non, émanant des établissements d'enseignement et de recherche français ou étrangers, des laboratoires publics ou privés. 


\title{
Time
}

Society

\section{Global Capitalism and the Critique of Real Time}

\author{
Wayne Hope
}

\begin{abstract}
Digital technologies globally interlink finance, production, consumption, mass communication, and cyberculture. The processes of interlinkage generate the sense that time is accelerating towards instantaneity. Promoters and critical observers of such developments have created a proliferating discourse of 'real time'. This key phrase and its associated terminology covers a diversity of referent spaces (e.g. cyberculture, financial flows, supply-chain management, on-line selling, live media events). In the context of global capitalism, discursive constructions of 'real time' are interrelated with new temporal constructions of systemic power. The nature of this interrelationship is obscured by the ideological features of 'real time' terminology. Here, this argument will be developed with references to popular business literature and (supposedly) critical academic writings. I conclude with a set of preliminary requirements for an effective critique of 'real time'. KEY WORDS • global capitalism • globalization $\bullet$ internet time $\bullet$ network time $\bullet$ real time $\bullet$ timeless time
\end{abstract}

\section{Introduction}

The interaction between global capitalism and converging digital technologies has generated a vast mosaic of computerized electronic networks. These networks transmit sound, information, images, and money at unprecedented speed. In this context, speed cannot be measured by the time taken to cover 
geographic distance. Electronically driven speed is immeasurably fast precisely because it transcends the obstacles and frictions of physical geography. Across networks, this kind of speed is measured against the standard of instantaneity. Consequently, efficient transmission is not assessed within the parameters of sequential clock time. Instead, the central question is - can lengths or lags of time be reduced or eliminated? This drive towards instantaneity within and between networks is encapsulated by the notion of 'real time'. Of course, real time can never accomplish full immediacy. In any given circumstance, there will always be tiny ineliminable lengths of time (Hassan, 2003: 231-3). Paradoxically, this observation reveals a distinctive feature of real time; it is a process of becoming rather than an empirical accomplishment. Despite incessant attempts by various agencies and organizations, real time never quite reaches full identity with itself. How then should one approach this increasingly pervasive term? My general position is that real time is deeply (but usefully) problematic rather than a misnomer. From a critical theoretical perspective, the referent spaces and associated terminologies of real time both illuminate and obscure the distinguishing features of contemporary global capitalism. In this regard, my argument can be outlined in advance. Materially, real time results from the interactions between globalizing capitalism and digital technologies. Ideologically, the language and imagery of real time obscure the socio-historical circumstances of its own emergence and proliferation. This precludes reflection upon the agencies' interests and classes who benefit from real-time formations. Together, these insights allow one to critically examine two inherent shortcomings of real time - uncertainty and instability. Against this background, I will outline the preliminary requirements for an effective critique of real time.

\section{Material Constructions of Real Time}

My purpose here is to contextualize the emergence of real time without resorting to economic or technological determinism. This account will suggest that real time networks intermesh with finance capital and exacerbate inter-temporal contradictions within capitalism as a whole. These same networks effectively constitute new temporal configurations of structural power. This general analysis consists of four interlinked propositions.

\section{Information and communication technology infrastructures intermesh with global finance}

This development can be traced back to the disintegration of the Bretton Woods currency system, a pivotal component of the post-war economic order. The key episode was the United States' 1971 decision to suspend the convertibility of 
dollars into gold. By the late 1970s, western Europe and Japan had become major global competitors. Their growing trade surpluses and vast dollar holdings provided potential leverage over US economic policy. Initially, the US responded to its deteriorating external position by exploiting the international pre-eminence of the dollar. Simple credit creation enabled the US to buy up foreign companies, fight the Vietnam War, and finance military-political hegemony over the rest of the world (Beeson, 1998: 83-4). After dollar convertibility ended, credit expansion was no longer tied to national currency reserves. Internationally, public control over exchange rates and capital movements could not be sustained. Consequently, private financial institutions were able to generate credit beyond state regulation (Germain, 1997: 98). Furthermore, when the US funded its deficits by pouring dollars into the international system overseas, (European) banks began to accumulate dollar-denominated deposits outside of national jurisdictions. US banks did the same in order to escape Federal financial regulations (Beeson, 1999: 84). The Eurodollar market that emerged became part of a vast stateless banking system. The major players offered syndicated loans, international securities, currency trades, forward exchange contracts, options, and futures. These were instruments of speculation for finance companies, funds managers, and portfolio investors. And, the opening of national stock exchanges to foreign institutions helped to create an enormous global equities market. Within this market, financial products underwrote corporate mergers and takeovers. During the 1980s, major transnational companies strove to acquire large shareholdings across different countries. Financial institutions themselves concentrated their wealth, diversified their portfolios, and established branches in cities worldwide. The likes of Citicorp, Chase Manhattan, Warburg, Noumura, Merrill Lynch, Barclays, and Credit-Suisse First Boston exemplified the new forces of global capitalism (Martin, 1994: 253-78).

The globalization of finance capital necessarily depended upon computerized electronic networks. They were created out of microchip circuitry, switching technology and digitalization. Associated advances in telecommunications (satellite, cellular, optical fibre) extended and accelerated information transfers between computer terminals. Specific technological advances include highspeed internet link-ups which enable stockbrokers, institutional traders and personal investors to buy and sell shares concurrently in different stock exchanges. Similarly, fund transfers among banks are co-ordinated by the Society for Worldwide Interbank Financial Telecommunications (SWIFT). This international facility is jointly owned by over 1000 banks reliant upon interbank funds transfer (Gandy and Chapman, 1997: 126; Singh, 2000: 11, 33). Together, such developments have created an environment in which "more currencies, more diverse and complex financial assets are traded more frequently at greater speed and in substantially greater volumes than in any previous historical epoch' (Held et al., 1999: 255). 
The preceding account illustrates the double relation between finance capital and ICTs. This is a distinguishing feature of contemporary globalization and global capitalism. ${ }^{1}$ Such an assessment does not draw upon 'new era accounts of informational spaces' (Thrift, 1996: 1465). I concur with Nigel Thrift's eschewal of technologistic narratives which attempt 'to impose an additive and singular politics of time by hijacking history in the name of the new' (p. 1465). However, one should add a cautionary note. In this kind of debate, all protagonists hold prior views about continuity and discontinuity as drivers of historical change. Now, in my view, the double relation between finance capital and ICTs represents a distinct historical conjuncture in the development of global capitalism. Within this conjuncture, one should critically examine various manifestations of finance culture. Thrift's approach is markedly different. He lambasts those who regard environments like the City of London as 'a way station in an extra-ordinary world of speed and immediacy, dematerialized like the money it serves, the haunt of the ineffable real, a moment in the constitution of the monetary sublime' (pp. 1473-4). By contrast, Thrift adjudges that such a world is 'still, even given the growth in quasi-mediated interaction a world of ordinary human practices, which have a complex historical genealogy' (p. 474). Subsequently, Thrift delineates the successive introduction of the telegraph, telephone, and computerized communications in City of London work environments. There are three major difficulties with this micro-social, evolutionary perspective. First, it fails to mention that traders, investors, managers, and executives in the City of London inhabit a world which is complexly positioned within various overlapping capitalist class structures (domestic, European, trans-Atlantic, international). The inter-linkages among these class structures have changed substantially since the initial introductions of the telegraph and the telephone. Second, it is only trivially the case that the City of London constitutes 'a world of ordinary human practices' (p. 1474). In sociological terms, it is more accurate to characterize finance culture, internationally, as a cliquish world where electronic speed and the drive towards immediacy generate unusual work environments (Cetina and Bruegger, 2002: 162). Third, Thrift's perspective fails to acknowledge that finance cultures in different locations together constitute a multi-nodal financial system, which externally shapes discrete human practices. As I will subsequently argue, the drive towards instantaneity that characterizes this financial system implicates capitalist production, news media organizations, and consumer culture.

\section{Digital technologies fuse money, information, and economic activity}

As neo-liberal governments of the 1980s deregulated banking, credit flows, and exchange rates, digital technologies accelerated global monetary exchange. This was an historically new phenomenon. The rapid movement of finance capital 
blurred with the technological means of that movement (Wark, 1994: 171). Increasingly, global finance was mobilized by business information networks and public news networks. In times of financial crisis, such as a Wall Street/ Nasdaq crash, 'bitstreams' of information and imagery jump unpredictably from network to network. Consequently, news flows and financial flows become overlapping. The major vendors of financial/economic data and related news content are Reuters, Knight Ridder, AP Dow Jones, Bloomberg, AFX, and Telerate. Their application of networking technologies provides relevant and reliable data feeds to end users. Correspondingly, global trades and transactions depend upon the most accurate and recent information available. News and data vendors also promote themselves as analysts of financial data. Reports about major indicators (e.g. exchange rates, stock values, interest levels, commodity prices) identify salient market trends. In this context, Reuters Holdings performs a strategically central role:

Banks, multinational companies, 'electronic brokerages' of all kinds - traders, speculators, governments and central banks - monitor price movements via Reuters terminals, served by Reuters systems; these include trading-room facilities and related transaction products. Transactions products became a major revenue earner for Reuters Holdings plc, the company floated on the Stock Exchange in 1984. Reuters serves multinational media and non-media clients worldwide by offering real-time multi-media and online systems and services, and is itself midway between Mammon and Mercury: the latter, the winged messenger of antiquity, is patron saint of journalists and of commerce. (Palmer and BoydBarrett, 1998: 67)

Within financial cultures, the fusion of money and information occurs through the screen. A recent study of foreign-exchange dealing rooms suggests that the market on screen is a 'whole' market consisting of information feeds and dealing systems. These components are 'configured to form a global picture framed by the boundaries of the screen, which also serves as a medium for transactions' (Cetina and Bruegger, 2002: 163). Within the dealing room of a major bank, an array of screens represent the content and the context of the market. An electronic broker screen displays currency pairs, price action, and recently completed deals. Another screen enables foreign exchange dealers to converse and contract on-line. Further screens display the currency positions of other banks and the commentaries of financial analysts. The entire process depends on 'the specificity, speed and currentness of the information' (p. 166). The authors of this study argue that markets are constantly processing newly arriving financial information. In this sense, 'the defining characteristic of the market as an agent is its lack of objectivity and incompleteness of being, its non-identity with itself' (p. 168). This comports exactly with the defining feature of real time. The drive towards electronically networked instantaneity never reaches completion. In the process, however, information and money are fused together. 
Within public news networks, media representations of economic activity help to constitute that activity (Hope, 1998). Previously, under Keynesian governments, academic economists, private-sector forecasting groups, and public servants provided the referent space of the national economy. In this context, news journalists relayed statistical and normative indicators of economic performance. Public debate centred around rival interpretations of growth figures, consumer price movements, trade balances, and employment levels. Once neo-liberal governments opened up national economies to global finance, bankers, currency traders, stockbrokers, and investment analysts became the primary sources of economic information. Now, the various agencies that define, index, and narrate the categories and rules of the (financially driven) economy make the economy exist by providing the flows of information that nominate it (Wark, 1994: 206). At the same time, the worldwide commercialization and deregulation of national broadcasting systems have encouraged the spread of advertising, infomercials, and corporately sponsored current affairs programmes. In this environment, media representations of financially defined economic activity merge with the promotion of business and consumer culture.

\section{Capitalism in general is driven by contradictory temporal imperatives}

The digitally driven (near) instantaneity of finance capital colonizes the slower, sequential time frames of productive capital. However, this temporal incorporation is neither a total or final accomplishment. Within macro- and microeconomic settings, short-term profit imperatives may damage the longer-term requirements of production and accumulation.

The colonization process occurs because financial assessment is no longer the sole preserve of banks. The risks of investment are redistributable to anyone able to secure (short-term) margins of profit. Thus, a complex web of financial interdependence is woven between companies and countries via the arbitrage of interest levels, exchange rates, currency values, and creditor-debtor positions (Aglietta, 1999: 69). Arbitrage activities exploit time differentials across space such that money appears to generate more money without direct involvement in production processes. Hedge funds draw upon major investment banks to exploit the speculative dynamics of top-level real estate, currency markets, and stockmarkets. Crucially, however, speculators with access to global finance determine the (high-interest) lending criteria for individual enterprises, industrial sectors, and governments. Additionally, the speculative logic of high-end arbitrage destabilizes exchange rates and undermines long-term planning for production. Projected export returns cannot be reliably calculated (Altvater, 1998; Singh, 2000: 88-98).

The short-term profit imperatives of global finance impact upon global equities and company performance. Different firms in different product markets 
become locked into competition for the attention of international providers of capital and technology. To maintain access to such vital resources, the firm must produce greater profits each year in relation to other firms against which it is competing for capital to finance new growth. This means firms must outperform the market in order to avoid takeover and/or dismemberment. Outperformance (in relation to other companies) may be measured in terms of share price, internal cost structures, access to low-interest loans, or the installation of new technology. All of these factors are assessed by institutional equity investors, investment analysts, and credit- and risk-rating agencies (Lepper, 1996: 21; Blackburn, 2002: 185). Consequently, poorly rated firms experience the constant threat of restructuring, divisional sell-offs, hostile mergers, or leveraged buy-outs. A 2001 comparison of Siemens Group and General Electric illustrates the prevailing measure of company performance (Benoit, 2001: 28). During the late 1990s, Siemens had experienced widespread divisional restructuring; key businesses included industrial automation, medical equipment, mobile phone networks, automobile electronics, rail equipment, IT services, and electric power. In 2000, Siemens declared a total operating margin of 3.6 per cent. However, investment analysts raised concerns about modest profitability relative to 'best in class' competitors. Over the same period, General Electric achieved a 21.6 per cent operating margin. In comparing the two figures, one analyst commented that 'Siemens unlike GE is not a company that is being run for cash'. During 2001, Siemens sought to spin off cash while driving down costs. They reduced the capital tied up in property, manufacturing plants and equipment and cut 15,000 telecom-related jobs (p. 28).

For capitalism in general, this kind of profit maximization is unsustainable. As a general principle, money capital has to be realized through production; productive capital must be realized in commodity form and commodities must be realized as money. Furthermore, as David Harvey (1999) observes, investment in physical and social infrastructures requires an extension of the realization process:

There must be surplus capital and a form of organization - usually the state but sometimes a powerful group of financiers - capable of centralizing the surplus capital, putting it into the creation of certain use values and waiting several years before reaping any reward. This also implies a conscious recognition and anticipation of capitalism's future needs. (p. 409)

In practice, however, the realization of capital cannot be guaranteed. Some capitalists may choose to accelerate their rate of profit within discrete spatiotemporal environments. In Das Kapital (1970), Marx identifies this tendency. The use of money to facilitate commodity exchange (C-M-C) is distinguished from the use of money to purchase commodities for exchange value (pp. 146-55). The C-M-C sequence is premised on the extraction of surplus value from labour 
during the production process. In M-C-M, money becomes an end in itself (Merchant Capital). When money lending occurs, M-C-M is reduced to M-M (p. 164). This is money exchanged for money, a sequence which disrupts the circulation of commodities and the realization of capital.

Today, digitally driven finance capital perpetuates self-contained M-M circuits which are parasitic upon productive investment and infrastructural development. This contradiction is publicly thematized whenever financial markets collapse. When this eventuality incorporates shares, property equities, currencies, and whole industries, affected capitalists may favour planned growth scenarios. If these do not eventuate, the unpredictable inter-dependencies of global capitalism will exacerbate volatility throughout the global financial system. And, further speculative collapses will spread more rapidly with yet more damaging economic effects. Internationally, developing countries will then try to regain control over their external accounts and 'hot money' capital flows. They may also insist upon economic policies that challenge the established rules of international financial architecture (Soederberg, 2002: 175-92).

\section{Within global capitalism, real time flows and networks generate temporal dimensions of structural power}

The installation of ICTs throughout the upper reaches of capitalism coincided with growing socio-economic polarization. In 1998, the United Nations Human Development Report identified the property, income and consumption indicators of global wealth and poverty. The three richest people in the world had assets that exceeded the combined gross domestic product of the 48 least developed countries. The world's 225 richest individuals had a combined wealth exceeding US\$1 trillion. This equalled the annual income accruing to the poorest 47 per cent of the entire world's population (cited in Sardar, 1999: 193). A more recent United Nations study into the world's 49 least developed countries calculated that 307 million people live on less than a dollar a day. This number was predicted to reach 420 million within 15 years (United Nations, 2002). At the same time, polarizations of wealth have become less circumscribed by territorial geography. There are no longer strict cartographical distinctions between the First, Second, and Third Worlds. The Second World has disappeared, while First World-Third World relationships of immiseration and exploitation take shape within regions, countries, and cities. The configuration of such relationships also stretches across territorial boundaries. Worldwide, the richest elites belong to a networked global culture of business, politics, diplomacy, entertainment, and information that ex-excommunicates the poor wherever they may be. The temporal nature of this process is succinctly described by sociologist Zygmunt Bauman (2000): 
People who come closest to the momentariness of movement are now the people who rule. And it is the people who cannot move as quickly, and more conspicuously yet, the people who cannot leave the place at all, who are ruled. Domination consists in one's own capacity to escape and the right to decide one's speed while simultaneously stripping the people on the dominated side of their ability to arrest or constrain one's own moves or slow down their velocity. (p. 179)

Within lifeworlds of impoverishment, such as wage labour, rural labour, benefit dependence, incarceration, homelessness and forced migrations, time is experienced as an imposition. Time is exhaustion, boredom, uncertainty, or fate. From within local conditions of imposed temporality, it is difficult to comprehend the historical processes of structural power. And, the exercises of such power are remote from those subjects who experience the consequences.

These observations reflect the findings of a recent urban poverty study. Jennifer Wolch and Geoffrey DeVerteuil (2001) investigated the appearance of the homeless, the mentally disabled, and other marginalized populations on the streets of large North American cities from the early 1980s. The authors outline how Fordist production, consumption, and an expansive welfare state gave way to a post-Fordist accumulation regime based upon capital mobility and 'flexible' labour management strategies. This transition 'intensified the scale and scope of social dislocation' (p. 158). As Federal and State governments instituted neoliberal policy agendas of privatization, welfare retrenchment, and 'workfare', the casualities of social dislocation became publicly obvious. This trend was exacerbated by municipal budget cuts, the gentrification of inner-city housing, commercial redevelopment, and the self-enclosure of middle-class suburbs. Meanwhile, image-conscious city administrators seeking to attract global capital acted punitively against marginalized populations. Aggressive policing, the employment of private security firms, criminalization of the homeless, and the 'cleansing' of parks were designed to remove the destitute from public view.

Together, all of these developments effectively shaped the spatio-temporal lifeworlds of the poor. In this context, Wolch and DeVerteuil (2001) detailed how specific marginalized groups negotiated the difficulties of everyday life. They found that the experiences of women in a central Los Angeles emergency shelter (during 1997 and 1998) were characterized by day-to-day uncertainty. Upon arrival at the shelter, 20 per cent of the women had spent the previous night on the street at a bus station or in a car. A further 25 per cent had spent the previous night at a shelter or transitional facility (p. 165). A similar study of the mentally ill revealed a common experience of 'individual time-space instability' (p. 166). From a group of 32 mentally ill patients released from hospital, 20 had spent 59 per cent of their last five years moving through various institutional settings such as emergency shelters, clinics, jail (Hopper, 1997, cited in Wolch and DeVerteuil, 2001: 166). Wolch and DeVerteuil conclude that 'new poverty management strategies and settings work through a divergent set of time-space 
cycles, temporally independent yet unsynchronized, from the global and national to the individual and institutional' (p. 168).

From a labour management perspective, electronic information systems allow transnational corporations, such as Nike and McDonald's, to decentralize operations while centralizing control. Senior executives consult updating spreadsheets in order to monitor factories and franchises worldwide. Global homework industries, such as Benetton "network computers, tie suppliers to sellers, match production to inventories, monitor dispersed workers and check quality and speed of supply through every ring of the hierarchy' (DyerWitheford, 1999: 136). Under these circumstances, fragmented and/or subcontracted workers lose the capacity to shape rhythms of life for themselves.

\section{Ideological Constructions of Real Time}

The drive towards real time has proliferated beyond the arcane worlds of high finance, info-tech innovation, and corporate management. The material and discursive extensions of real time can be categorized as follows:

- The incursions of finance and investment culture into the mass media domain, public institutions, and civil society;

- The surrounding presence of global television and live global media events, scripted and unscripted;

- The commodification of immediate experience via corporate branding and advertising. Global culture industries conjoining film, music, fashion, and sport promote the 'now-ness' of pleasure, desire and gratification;

- Cyberculture generates the illusion of disembodied real-time experiences, for example video games, virtual communities, tele-presence, immersive virtual reality;

- Urban, suburban, and 'exotic' real-time experiences, for example theme parks, shopping malls, moving billboards, expos, related tourism experiences.

These manifestations of real time are densely connected across space and between places. Thus, finance culture merges with global news networks and various cybernetworks of sharemarket investment. In contemporary city environments, architectures of spectacular consumption fuse with the global culture industries. Within cyberculture, multi-media software provides immediate access to the commercial mass media. And, suburban malls incorporate households within cyberworlds of interactive shopping.

Discursively, the proliferation of real time is a central ideological feature of global capitalism. Here, I view ideology in pejorative terms as a symbolic construct that serves to reproduce prevailing relations of power. However, symbolic constructs such as language, imagery, and technological formats are not 
always ideological. When this is the case, the ideological character of symbolic phenomena cannot be simply read off from the phenomena themselves (Thompson, 1994: 56). One must demonstrate how background relations of power are served. Thus, it can be said that the discursive formations of real time perform ideologically if it is demonstrable that the socio-historical origins of these formations are obscured from public view. One should also recognize that symbolic forms may constitute and obscure social reality; the material and the ideological are deeply intertwined. The array of screens in a foreign exchange room, for example, enables the circulation of finance capital and the ideological promotion of finance culture. Finally, the obfuscatory character of ideological rule should not be equated with falsehood such that critique is a function of truth. This binary opposition overlooks the complex relationship between social formations and social knowledge. Real time, for example, is a multiple phenomenon that imparts truths about the contemporary world while giving a distorted picture of it. The critical point is that identifiable formations of real time often serve to sustain and naturalize prevailing relations of power. To this end, real-time ideology obfuscates questions of agency and historical context. It is to this process that I now turn.

\section{The real-time economy}

Increasingly, real-time terminology serves as a descriptor of economic and business activity (Tapscott, 1996; McKenna, 1997; Ranadive, 1999). A recent Economist feature entitled 'How About Now?' (Siegele, 2002) surveys various aspects of 'the real-time economy'. The empirical and temporal significance of the central locution is clearly stated:

Real time is more real than it appears. The start-ups in this field are leading the counter-revolution to the dot com mania. They are not about all-too-clever business models and breathless 'internet time' (for which read going public as quickly as possible), but about highly complex enterprise software often based on serious mathematics that can yield real savings if deployed and used correctly.

Most important, perhaps, the concept of real time is more useful than the somewhat artificial distinction between the 'old' and 'new' economy. Real time describes the full potential of what information technologies could ultimately do, according to Andrew Odlyzko, director of the Digital Technology Centre at the University of Minnesota: drive the lags and latencies out of the economy and make it much more efficient. Real time technology might even prove as important for speeding up the information flow in business as the telegraph, invented in 1837. (p. 4)

The preceding extract from an authored introduction identifies two kinds of realness. The superficially apparent realness of real time is manifest in 'dot com mania' and 'breathless internet time'. The other kind of realness is about 'high- 
ly complex' software and 'serious mathematics'. Such qualities can potentially yield 'real savings'. In the latter sense, real time is assumed to be an authentic, verifiable construct that delivers tangible results. The contemporary, mathematically grounded reality of savings compares more than favourably with the 'all-too-clever' unreality of the dot com era. The newly promoted version of real time derives from the capacities of 'enterprise software' and 'information technologies' in general. This expert assessment (from the director of a University Digital Technology Centre) is simply taken for granted. But such a view is couched within a technologically and commercially defined narrative of progress. Like the telegraph, today's technologies are 'speeding up the information flow in business'. This reconstruction of the past eschews the societal and normative contexts of technological development. It is assumed that technology drives history in a progressive direction. And, the benefits of progress are measured by successive accelerations in the speed of business operations.

This account of real time also makes reference to 'the economy'. Within this abstract locution 'the ...' implies a sense of universal being. Widespread talk about 'the economy' silences those representations that express the capitalist nature of that economy. If the capitalist adjective is used then the fundamental nature of such an economy is brought into sharp focus. Before the neo-liberal era 'the economy' was depicted as a specifiable entity requiring expert management for rational ends (e.g. as in the economy needs to be managed, developed, or expanded to achieve growth). Within such discourse, geographic qualifiers were common (e.g. as in 'the national economy', 'the Australian economy' or 'the international economy'). Such usages became less common under neoliberalism. Instead, a complementary deployment of the key locution prevailed. In a general sense, 'the economy' became dynamic and self-operating by nature. In this context, the presumed superiority of neo-liberal capitalism was revealed in phrases such as 'the free market economy' or 'the market economy'. Here, the implication is that older versions of 'the economy' were anachronistic by definition. Now, in the extract under review, 'the economy' transcends all sense of historical change. This is a two-step process. First, against the 'concept of real time', the distinction between 'the old and the new economy', is deemed 'somewhat artificial'. Second, real time (as an effect of information technologies) removes all temporal contaminants from 'the economy', that is, real time drives out 'the lags and latencies'. However, this cannot be a final accomplishment because real time as such, is a process of becoming. Its meaning derives from what lies beyond; the tractable other ('lags' and 'latencies'). In its own right real-time merely describes 'the full potential' of what information technologies 'could ultimately do'. In the meantime, overcoming 'lags' and 'latencies' is the prevailing indicator of progress.

The Economist feature proceeds to identify further real-time environments and issues. In corporate management, General Electric is reported to be 'setting 
up a digital nervous system that connects anything and everything involved in the company's business: IT systems, factories and employees as well as suppliers, customers, and products'. The Chief Information Officer remarks that 'GE's aim is to monitor everything in real time' (Siegele, 2002: 3). In Silicon Valley, venture capital firms plus software and networking start-ups have adopted the discourse. Specific developments are recorded in a recently posted newsletter called Real Time Report (Siegele, 2002). The Economist also traces the key term back to the inaugural period of 'batch mode' data processing. Then, information was entered, stored, and worked on later. Now, 'data are processed the moment they enter a computer'. This is a simultaneous multi-terminal exercise. Prematurely perhaps, readers are told that 'modern spreadsheet software is as real time as it gets' (p. 4). Additionally, newly automated web server technologies allow firms to integrate their systems by hiring outside expertise. Web service programmes 'publish their data feeds following a set of internet standards so that other programs can easily subscribe to them' (p. 7). Real-time technologies are also central to supply chain management. As corporate manufacturing processes become 'increasingly dispersed and global' customers are 'getting more and more demanding'. They are looking for a customized solution or product 'delivered within days' rather than weeks (p. 11). The Economist feature goes on to declare that real-time technologies will 'transform the company as we know it' (p. 13). This projection is shared by Ray Lane, a partner with Kleiner Perkins Caulfield and Byers, a Silicon Valley venture capital firm. He reportedly says that in the long run real time technology will do away with all the features of a firm that were needed to assure information flow in an off-line world: hierarchies, departmental boundaries, paper shuffling employees' (p. 13). From this perspective, the entire off-line world is a barrier to the progress of real-time technologies.

In a section entitled 'Computers of the World Unite', it is acknowledged that the real-time economy 'will raise problems of its own' (Siegele, 2002: 15). These include the instability of automated information flows, the possible inaccuracy of information content and the multiple impact of external shocks (i.e. a stockmarket collapse, a terrorist bombing, or a military conflict). In the final analysis, however, such concerns are downplayed: 'Yet it would be wrong to conclude that the introduction of new information technology should be slowed down or even blocked altogether. Its drawbacks are not inherent in the technology itself, but arise from the way it is used' (p. 16). The message here is unmistakable. There can be no valid criticism of real-time information technology. It should be introduced with full momentum. Perceived drawbacks are restricted to the usage of technology. The application of real-time technology has no fundamental drawbacks because 'technology itself' is unassailable. In this context, technology is synonymous with the commercial priorities of share traders, corporate executives, financial planners, supply chain managers, 
systems analysts, and software engineers. In my view, their rush towards real time is itself the problem. Even from a global capitalist perspective, the proliferation of real time magnifies the realm of unpredictability in unpredictable ways. From within real-time environments, dangerous events are uncontrollable.

\section{Manuel Castells's trilogy: the problem of timeless time}

Manuel Castells's trilogy comprises The Rise of the Network Society (1996), The Power of Identity (1997), and The End of Millennium (1998). The first volume outlines the global contours of a network society based upon the 'space of flows' in contrast to the place-centred formations of industrial society (i.e. industrial capitalism and the supervening state). The new society centers upon a capitalist mode of production and an informational mode of development. According to Castells, this dual formation emanates from the global restructuring processes of the 1970s and 1980s. The collapse of Bretton Woods, Keynesian class compromises, and Fordist regimes of capital accumulation meshed with the growing centrality of information technology. With the demise of Soviet statism, capitalism worldwide became driven by electronic flows of information. For Castells, these convergent developments heralded a fundamental transformation of human society. An informational mode of development was taking shape whereby the generation of new knowledge was the key source of productivity and innovation. More profoundly, the conjoining of knowledge generation, information processing, and communication flows was, and is, producing a mosaic of networks. Generically, the network is driven by the logics of speed, spatiality, and flexibility.

Castells identifies a disjuncture between the networked space of flows and the space of places. In these circumstances, the territorial nation state can neither resist the power of networks (e.g. global communications, financial flows) or process localized political demands. Volume 2 of the trilogy argues that resistances to exploitation, inequality, and domination increasingly bypass state institutions. Within and across the space of places, resistance may cohere defensively in the form of religious fundamentalism, cultural nationalism, or regional communalism. Alternatively, new social movements such as feminism and environmentalism proactively engage with the logics of network society. What transpires is a globally configured politics of identity which contests the space of flows from within. In Volume 3, Castells delineates the collapse of state industrialism and the Soviet Union. Second-World demise is followed by the growth of a fourth world characterized by crime, squalor, and informational exclusion. Prime locations include Sub-Saharan Africa, urban American ghettoes, and Latin American shantytowns. Meanwhile, the state-led trajectories of East Asian development are superseded by informational mega-cities linked 
to hub-spoke networks of industrial production. In this regard, Castells cites the emergence of Hong Kong-Shenzhen-Canton-Pearl River Delta-MacauZhuhai metropolitan regional system (Castells, 1996: 407, 1998: 264).

My earlier discussion of global capitalism identified elements of historical discontinuity. Castells's trilogy makes a far stronger claim. History as narrative is deemed irrelevant. We are witnessing an irrevocable shift in the very nature of time. These propositions are first set out in a Volume 1 chapter entitled 'The Edge of Forever':

But we are not just witnessing a relativisation of time according to social contexts or alternatively the return to time reversibility as if reality could become entirely captured in cyclical myths. The transformation is more profound: it is the mixing of tenses to create a forever universe, not self-expanding but self-maintaining, not cyclical but random, not recursive but incursive: timeless time, using technology to escape the contexts of its existence, and to appropriate selectively any value each context could offer to the ever-present. I argue that this is happening now not only because capitalism strives to free itself from all constraints, since this has been the capitalist system's tendency all along, without being able fully to materialize it. Neither is it sufficient to refer to the cultural and social revolts against clock time, since they have characterized the history of the last century without actually reversing its domination, indeed furthering its logic by including clock time distribution of life in the social contract. Capital's freedom from time and culture's escape from the clock are decisively facilitated by new information technologies, and embedded in the structure of the network society.

The transformation of time as surveyed in this chapter does not concern all processes, social groupings, and territories in our societies, although it does affect the entire planet. What I call timeless time is only the emerging, dominant form of social time in the network society, as the space of flows does not negate the existence of places. It is precisely my argument that social domination is exercised through the selective inclusion and exclusion of functions and people in different temporal and spatial frames. (Castells, 1996: 433-4)

These passages reveal a central tension within Castells's analysis. Elsewhere, he argues that the information technology revolution underpins the emergence of informational capitalist economy (Castells, 1996: 69-71). Yet, the suggestion here is that capitalism has transcended any kind of historical development. Capitalism is now subsumed within a 'forever universe' of 'timeless time'. There are major problems with this judgement. First, timeless time appears to be a final, absolute accomplishment. Other temporalities are assigned to a life of perpetual subservience. This precludes the possibility that timeless time might be subject to the principle of finitude. Is it possible to contemplate the future demise of timeless time? What would bring it about? Correspondingly, Castells appears to be saying that timeless time contains no temporal contradictions. But, the history of globalization illustrates the opposite tendency. Colonizing processes, for example, entail the imposition of temporal regimes which are vulnerable to the counter-constructions of (anti-colonial) history. 
Second, the preceding extracts refer to 'capital's freedom from time'. This extraordinary formulation ignores evidence that capitalism experiences recurring cycles of growth and recession. Entire sub-branches of economics investigate the geo-historical character of capitalist cycles. More specifically, financial historians trace speculative booms and busts over time. Today's boom-bust scenarios certainly possess unique features, however, the phenomenon itself remains historically recognizable. Furthermore, as suggested earlier, it is evident that dominant fractions of capital operate against temporal limits. Thus, the extraction of monetized profit from the circulation of capital cannot be indefinitely sustained (M-C-M and M-M). Financially engineered enterprises such as hedge funds and dot com companies require guaranteed credit lines. When this requirement no longer holds such enterprises are wound up. Neither can M-C-M and M-M patterns of investment sustain capital as a whole. Sooner or later some profit must be reinvested in raw materials, plant, machinery and human capital.

This general observation reveals that capitalism as a whole is torn between conflicting temporalities. The prevalent, hyper-speed time of finance capital is at odds with the strategic outlook of large-scale production. It is therefore absurd to suggest that capital in general can escape from time. Under global capitalism conflict over temporal priorities is a defining feature of investment and business operations. Thus, pension funds can be an on-going resource for short-term returns or long-term social investment. Similarly, the Enron collapse reveals that strategic planners and financial engineers battle for power within corporate boardrooms (Blackburn, 2002: 188-93). And, within manufacturing enterprises supply-chain management is a contested science; enthusiasts for real-time solutions confront risk-averse resource planners.

Castells's simplistic generalizations about time and capital inform his account of global finance. In a subsection entitled 'Time as a Source of Value: The Global Casino' he states that

during the 1980s the convergence of global deregulation of finance and the availability of new information technologies and new management techniques transformed the nature of capital markets. For the first time in history a unified global market working in real time has emerged. The explanation and the real issue of the phenomenal volume of transborder financial flows lies in the speed of the transactions. (Castells, 1996: 434, emphases in original)

Now, the interaction between finance capital and the new information technologies is, indeed, a historically significant development. But Castells's understanding of this development lacks conceptual nuance. In the context of previous declarations about 'timeless time' the 'real time' of the 'global capital market' appears absolutely unassailable. In fact, however, the drive towards instantaneous financial flows inherently magnifies the instability and unpredictability of 
capitalism as a whole. In given circumstances this may strengthen the case for international capital controls. Castells (1996) clearly recognizes the dire consequences of unregulated finance. He refers to 'recurrent monetary crises' and 'the inability of capital investment to anticipate the future' (p. 436). The problem is that such insights are not conceptually grounded. Castells never acknowledges the problematic nature of real time itself. In particular, he fails to realize that real-time financial flows may be restricted or threatened by other temporal logics. For example, the likely consequence of a full-blown global slump would be a massive slowdown in macro-economic activity.

For Castells (1996) timeless time radically reorders the relationship between time and space. And, this accomplishment effectively terminates past formations of history:

Space shapes time in our society thus reversing a historical trend, flows induce timeless time, places are time bounded. The idea of progress at the roots of our culture and society for the last two centuries was based on the movement of history under the lead of reason and with the impulse of productive forces escaping the constraints of spatially bounded societies and cultures. (pp. 466-7)

In my view this general argument fundamentally misconstrues the idea of progress. Under western industrial capitalism progress was the ruling myth of historical change. The advancement of capitalist interests could be obscured by the presumption that progress was universal. From this perspective history always culminated in a present which was, realistically, the best of all possible worlds. And, this process of culmination was driven by (apparently) ineluctable forces of science and technology. These forces were channelled and steered by the quality of reason. At the same time counter-movements of class, gender and cultural emancipation deployed human or cultural conceptions of progress against capitalist definitions of the term. From this vantage point the capacity to reason enabled human freedom.

Now, however, progress is disconnected from linear historical narrative. Under global capitalism the ruling myth of progress is synonymous with the ideology of real time. Thus, finance culture and info-hype celebrate the drive towards instantaneity. As I have indicated, real time proliferates outward to include ever more domains of socio-cultural activity. Each new real-time application is a signifier for today's version of the progress myth. Instantaneity is the goal; whatever prevents it is an obstacle to progress. Simultaneously, real-time tendencies are myopic and unstable. When such tendencies are manifest the instantaneous space of flows is vulnerable to counter-conceptions of reason, temporality and progress. On this analysis, the space of flows and the space of places are shaped by the inescapable problematics of time. Castells's ideal of timeless time is mythic because it implies that this temporal realm is beyond human influence. It seems that timeless time was born to rule. 
Castells also misconstrues the relationship between global capitalism and the exercise of structural power. This is evident in his discussion of polarization. Here, The End of Millennium contains a section entitled 'The Rise of the Fourth World: Informational Capitalism, Poverty and Social Exclusion' (Castells, 1998: 70-165). Castells begins by discussing the quantitative and qualitative dimensions of polarization in relation to inequality, poverty, misery, social exclusion, and over-exploitation. He then examines the economic and geographic dimensions of global polarization. He concludes that 'there is polarization in the distribution of wealth at a global level, differential evolution of intra-country income inequality and substantial growth of poverty and misery in the world at large and in most countries, both developed and developing' (p. 82).

Castells also examines how global polarization is structurally generated and socially experienced. Cited examples include Sub-Saharan Africa, West Africa, urban-American ghettoes, American prisons, and the worldwide exploitation of children (Castells, 1998: 82-159). Castells's overview of global polarization is flawed because the spatio-temporal concepts which govern his trilogy are too enveloping. Consequently, the temporal dimensions of global polarization are precluded from analysis. This is evident in the following passages:

By secluding power in the space of flows, allowing capital to escape from time and dissolving history in the culture of the ephemeral, the network society disembodies social relationships, introducing the culture of real virtuality.

... by real virtuality, I mean a system in which reality itself (that is, people's material/symbolic existence) is fully immersed in a virtual image setting, in the world of make believe, in which symbols are not just metaphors but comprise the actual experience. This is not the consequence of electronic media although they are the indispensable instruments of expression in the new culture. The material basis that explains why real virtuality is able to take over people's imagination and systems of representation is their livelihood in the space of flows and in timeless time. (pp. 349-50)

Here, Castells claims that 'timeless time', the 'space of flows' and the 'culture of real virtuality' envelop social consciousness. But such a perspective overrules earlier analyses of polarization. Informational capitalism cannot, simultaneously, dualize and subsume collective social experience. If Castells adopts the dualistic view then he must explicate the temporal dimensions of global polarization. If he emphasizes the subsuming power of his governing concepts then the theoretical significance of polarization must be clarified.

\section{Temporalities and networks}

In the preceding excerpts, 'the real time economy' and 'timeless time' are selfdefining master locutions. They represent large-scale processes as phenomena that take place in the absence of any subjective interest. It seems as though these 
mega-temporal constructs have simply arrived without agency or material design. John Thompson (1994: 66) classifies this kind of ideological operation as passivization. Linguistically, this occurs whenever key terms and phrases are not acted upon by verbal constructions that refer to actors or agency. Within popular business literature and info-tech hype, terminologies associated with the notion of real time are passively rather than actively constructed. This is hardly surprising in places where new terms and phrases are deployed for promotional purposes. Less obviously, critical writings on temporality often contain passivist locutions that detract from or clash with adjacent lines of argument. Castells's discussion of 'timeless time' is a case in point. The same tendency occurs in Robert Hassan's article 'Network Time and the New Knowledge Epoch' (2003):

Network time is digitally compressed clock-time, and as such operates on a spectrum of technologically possible levels of compression. This spectrum is open ended. At one end this may last from a few minutes or seconds, when waiting for a download or for chatroom text to reach the recipient, to, at the other end of the scale, nano- or picosecond transmissions, which are one billionth and one trillionth of a second respectively. Time duration is limited only by technical capacities. However, the network is always, in some respects, asynchronous. Networks can fail for a time; they can experience heavy traffic loads that slow them down; emails can be received and read later, as can SMS and voicemail, and so on. They key issue is the network itself, and the general effect of the network is a generalized acceleration. (pp. 233-4, emphases in original)

Here, the key locution 'network time' is presented as a function of 'digitally compressed clock time'. Digital compression emanates from certain 'technical capacities' which can facilitate information exchanges within very short time durations. In sum, 'network time' is governed by the principle of 'generalized acceleration'. This is a passivist, self-defining formulation. The temporal construct under review owes its existence to the network and 'the network itself' is understood in terms of its temporal qualities ('compressed clock-time' and 'generalised acceleration'). The circular logic at work here clashes with later statements that $d o$ acknowledge casual agency:

Globalising capitalism and the ubiquitous computing that it depends upon mean that networks of interconnectivity are set to deepen and widen spreading its temporality across more and more realms of life.

... the network has its own meta-logic, one that stems from the imperatives of capitalist accumulation, production, and consumption. It reflects the social and economic forces that build it and is essentially market orientated and instrumental. (Hassan, 2003: 234 and 236)

Here, network time is related to historical processes which have systemic agency ('globalising capitalism'). However, the nature of this relationship is unclear. In the first passage, 'networks of interconnectivity' produce a temporality that drives 'globalising capitalism'. The second passage states that the 
network has a meta-logic of its own, and that it stems from the imperatives of capitalism. There are several related problems here. First, there is a discrepancy between the supposed independence of the network ('its own meta-logic') and the network's apparent dependence on an outside force ('capitalist accumulation, production and consumption'). Second, the nature of the relationship between capitalism and network time is never specified. Are they mutually reinforcing? Is one of them the primary force? Or, is the relationship contingent upon given circumstances? Third, the depiction of capitalism lacks historical grounding. Capitalism was 'globalizing' well before the construction of digital networks. Therefore, one must assess the extent to which digitally networked, capitalist globalization is a break with the past. Hassan cannot make this assessment because his view of capitalism is informed by an inconsistent definition of network time. Earlier, it appears as a digitally compressed version of clock time (pp. 233-4). Yet, in the first, preceding extract, 'networks of interconnectivity' are said to possess a distinctive temporality that is set to spread 'across more and more realms of life'. The initial definition emphasizes the continuity between clock time and network time, whereas the later extract infers that the historical relationship is one of discontinuity. In another passage, this inference is directly stated. Hassan writes that 'the growing number of ICT devices and applications that comprise the network ecology begins to shape our relationship to a new, emptied and de-temporalised successor to the clock - the network' (p. 235). Fourth, the depiction of contemporary capitalism in the preceding extracts is too generic. It can certainly be argued that the high-speed temporality that emanates from 'networks of connectivity' is congruent with the dynamics of global finance. However, this kind of temporality works against longer-term cycles of investment, production and commodity exchange. Hassan overlooks the fact that 'globalising capitalism' is riven by contradictory temporal imperatives. Furthermore, Hassan's discussion of ICT-driven temporality rests upon an undifferentiated conception of 'the network'. It is a mistake, in my view, to regard digitalized networks as an encroaching force that conforms to some kind of meta-logic (even if this logic is thought to cohere with the expansion of capital). A given network, or set of networks, may, simultaneously, generate patterns of inclusion and exclusion. This occurred when internet banking was introduced to British and American customers during the 1990s. The proliferation of new services coincided with extensive branch closures. Economically deprived areas without home internet facilities were the most likely to lose branches. Consequently, non-mobile and physically confined customers faced longer journeys to the bank (Leyshon, 2000: 437-8, 443). In cases such as this networks, necessarily, construct zones of exclusion. Furthermore, multi-scalar networks of high-speed interconnectivity effectively impose other temporal realms upon the excluded poor. As I have indicated, high speed or 'real-time' networks bifurcate rather than envelop temporal experience. Sociologically, this 
is an exercise of structural power whereby 'domination consists in one's own capacity to escape and the right to decide one's speed' (Bauman, 2000: 179). Those critical observations reflect an underlying semantic problem. Generic conceptions of 'the network' conflate technological and social meanings of the term. This is a crucial insight because the technological and the social may work against each other in practice. In given spatio-temporal environments, a technologically integrated network (or cluster of networks) may precipitate social disintegration. This occurs, for example, when a military network goes to war and when a networked corporation disinvests from a community. In each case, the activated network contains a technological and a social dimension, which are combined for systemic purposes.

Identifying the ruling formations of 'real time' need not entail a rejection of high-speed digital networks. They can also serve as a resource for oppositional modes of communication and mobilization across localities. However, it is difficult to make such a purposive distinction when locutions of temporality are passively constructed (i.e. 'the real time economy', 'timeless time', 'network time'). One way of circumventing this difficulty is to critique singular constructions of temporality from the perspective of local, co-mingling temporalities. Such is evident in the following passage from Soraj Hongladarom's article, 'The Web of Time and the Dilemma of Globalisation' (2002):

On the one hand, internet time can be an expression of domination of the local by
the global. Time ceases to be integrated with each different place, but becomes a
function of the global network. On the other hand, the internet itself makes it
possible for the locals to assert their own identities and to project their power viz a
viz the global. Thus it becomes possible for there to be both a single global time
and a multitude of local times. What is immensely interesting is that these times
exist together side by side as well as one on top of the other, at the same time.
(p. 224)

This passage identifies a singular, monopolistic construction of temporality; 'internet time' as a 'function of the global network'. Globally networked internet time dominates the local because it is detached from 'each different place'. Against this, 'the internet itself' is seen as a conduit for expressions of local identity in a global environment. These local expressions reflect 'a multitude of local times'. Furthermore, the internet enables local temporalities to co-exist 'one on top of the other at the same time'. Here, the global, networked version of internet time appears as a continuous process without interest or agency. Consequently, a global, singular temporality is set alongside local co-mingling temporalities without reference to the power structures involved. Conversely, the circumstances under which local temporalities might, in principle, successfully contest global internet time are not mentioned. This occurs because 'the internet itself' is a generic, self-enclosed locution that precludes the possibility of definitional argument. In practice, the internet enables multiple forms of 
computer-mediated communication, which reflect socio-cultural norms and prevailing relations of power. Thus, internet-related infrastructures are the nervous systems for e-commerce, the circulation of finance, equity trading, corporate governance, military campaigns, and state surveillance. Alternatively, the internet operates as a cyber-bulletin board, a mobile library, a diary of record, and as a tool for off-line political mobilization. These competing manifestations suggest that socio-cultural understandings of the internet are essentially contested within society and over time.

Hongladarom's decontextualized juxtaposition of singular temporality and multiple temporalities reflects a deeper problem. She provides undifferentiated conceptions of the global and the local and presents them as binary opposites. Either the global effects 'domination of the local' or 'the locals assert their own identities' and 'project their power vis-à-vis the global'. These formulations make it difficult to comprehend how temporalized conflicts of power might play out within the local (such conflicts may have national and/or global repercussions). Conversely, it is hard to determine the kinds of temporalized conflict that might play out within the global (these may have national and/or local repercussions). Elsewhere, Hongladarom refers to a debate within Thailand over the government's proposal to change the country's standard time (from seven hours ahead of Greenwich Mean Time to eight hours). This would put Thailand into the same time zone as Hong Kong and Singapore, making financial transactions easier. Opponents of the move asserted the right of Thai citizens to set their own clocks. Hongladarom (2002) concludes that 'this example shows a real case of the conflict between globalisation and the moves to resist it' (p. 246). This again assumes that the global and the local are generically and temporally opposed to each other. As I have argued, this is not exclusively the case. Inter-temporal conflict occurs within, as well as between, global and local environments.

\section{Towards a Critique of Real Time}

My critique of real time builds upon the following definitional insights. Digitalized electronic networks generate a speed of communication that drives towards instantaneity. This differs from a conception of speed which is measurable by the time taken to cover geographic distance. The latter form of speed is a manifestation of linear, sequential clock time. In contrast, the drive towards instantaneity within and across networks can be characterized by the notion of 'real time'. This locution should be seen not as a misnomer, but as a resource for analysis and critique. Thus, the referent spaces and discourses of real time allow one to identify the distinguishing features of contemporary global capitalism. One should also recognize that real time serves to efface the sociohistorical conditions of its own emergence and proliferation. Materially, real 
time is not an empirical accomplishment, but a process of becoming. Instantaneity and immediacy are not fully attainable; lags of sequential time stubbornly remain. Yet it is this drive towards an unrealizable objective that characterizes the installation and proliferation of real-time networks throughout the capitalist world.

From here, one must develop an historically informed critique of real time. To this end, I have argued that material and ideological formations of real time emanate from the historic convergence between global finance and digital technologies. This convergence can be understood as a double relation in two senses. In general terms, digitalized networks form the infrastructure of a financial system that invests in the expansion of infotech corporations. More specifically, digitalized communication networks are also financial networks and this dual function fuses money and information. But networks of real time do not simply result from a complex process of development. The process is shaped by ruling interests such as financial institutions, ICT companies, and other transnational corporations. Such interests are exercised through the activities of foreign exchange dealers, system engineers, corporate executives, and other specialized professionals. Together, they create a vast mosaic of real-time networks which underpin the architecture of contemporary global capitalism. Acknowledgement of this reality allows one to critique passivist locutions of temporality that delete or marginalize agency, that is, 'the real time economy', 'timeless time', 'network time', 'internet time'. Tracing the emergence of 'realtime' formations within surrounding relations of power provides an historical framework for understanding more recent developments.

Since the early 1990s, financial, corporate and ICT-related formations of real time have proliferated outward to incorporate mass communication, popular culture, and built environments. However, this is not a seamless, ineluctable tendency. The drive towards instantaneity that characterizes the congruence between global finance and ICTs is problematic for capitalism as a whole. Short-term circuits of financial profit undermine the longer-term cycles of capital realization. When this inter-temporal contradiction is actualized via the collapse of currency values, stock prices and/or major corporations, interacting formations of real time become disorganized. Such occasions require special investigation. If one traces the interplay of events and their socio-economic consequences a disturbing picture emerges. The real-time formations of global capitalism generate temporal dimensions of structural power. Worldwide, the richest elites benefit from networked systems of immiseration, exploitation and excommunication. They have the capacity to enter or exit from real-time environments (for the purposes of work, travel, leisure, entertainment or knowledge acquisition). These insular webs of social activity effectively produce a bifurcation of temporal experience. In slums, prisons, refugee camps, and isolated rural areas, millions of human beings are forced into life-worlds of uncer- 
tainty, fear, exhaustion, and fate. These temporal experiences are configured by, yet dislocated from the real-time networks of global capitalism.

My preceding, historically grounded explication of real time can be supplemented by immanent critique. The drive towards pure, networked instantaneity is unrealizable, but the process of trying to reach this objective magnifies the instability and uncertainty of (attempted) real time formations. The very notion of full instantaneity means that the past cannot act upon the present. And whenever attempted instantiations of real time unfold, the future cannot be planned for. This raises the possibility that unanticipated events might damage or threaten attempted actualizations of real time. The drive towards instantaneity, therefore, is inherently myopic and fragile. Such weaknesses can only reoccur given the absence of learning capacity within the real time impulse itself. Discursively and symbolically, the logic of real time has two primary manifestations. They are closely connected and, in given circumstances, inseparable. First, real time (and its associated terminology) operates as a self-enclosed variant of technological determinism. Within info-tech literature, for example, the real-time features of digital networks enable the accomplishment of real time objectives. This circular logic ensures that technology itself is beyond scrutiny. In specialist terms, real-time objectives are always the subject of technical recalibration or redefinition. And, specifying such objectives, justifies the means of getting there. Second, the circular logic of real time is built into certain representations of the economy and the market. As a linguistic abstraction within financial, corporate, and neo-liberal discourses, the market appears selfoperating, self-defining, and ahistorical. Throughout the screened interiors of global financial activity, technological determinism and market determinism are mutually reinforcing. This doubled unfolding of real time never reaches full identity with itself.

The next step is to develop a multi-faceted, normative critique of real time, which does not entail a technophobic rejection of high-speed digital networks. This approach invokes countervailing principles of temporality. Thus, in political environments, electronic communication networks should facilitate rather than subsume the slower temporal rhythms of democratic deliberation, representative assembly, and leadership succession. From a macro-economic perspective, rapid transfers of money, information, and knowledge must fit the temporal parameters of planned development within localities, regions, and nations. Additionally, ICT networks ought to foster the language, symbols, and cosmological heritage of non-western cultures. Inherent to these requirements is the principle of temporal pluralism within societies and between places. On a global scale, internet forums and networks can nurture intra-diasporic communication and facilitate ecumenical exchanges among religious groups. Such developments reveal how various cultural epistemologies of time contribute to world history. It is equally important to respect the spatio-temporal embeddedness of 
states, nations, and societies. To this end, computer-mediated communication can interlink territorially defined traditions of governance and administration. Within territorial places, internet connectivity can provide knowledge for the sustenance of individuals, communities, and civic associations.

Thus far, I have outlined the historical context of real time, suggested grounds for immanent critique, and proposed normative criteria for the constructive use of high-speed digital networks. Politically, it is important to identify and oppose the information and financial networks which generate global systems of power (the international debt crisis, structural adjustment programmes, transnational systems of worker exploitation, corporate control of the world food system, and international, inter-regional, and bilateral regimes of 'free' trade). Clearly, opposing the ruling interests involved requires worldwide coalition building among worker organizations, ecology action networks, rural farmer activists, indigenous cultures, religious creeds, and human rights groups. Already, the experience of coalition building has engendered a global sense that alternative futures are possible. An empirical outline of the desired futures for global governance, economic development, and world resource distribution is beyond the scope of this article. My general point is that only a global consciousness of historical momentum can bring such alternatives to light. But, for this to proceed, it will be necessary to de-reify the myth that the drive towards real time is a signifier of progress. As I have demonstrated, adherence to this myth has proved to be myopic and destructive. Therefore, a new collective sense of progress must be launched against the real time determinism of global capitalism.

\section{Notes}

1. Historically, globalization refers to those spatio-temporal processes of change that interconnect human activity across regions and continents. One standard reference work identifies four spatio-temporal processes (Held et al., 1999). Extensity refers to the global reach of regional events, decisions and activities. Intensity concerns the magnitude of global interconnectedness. Occasional travel between highly disparate localities contrasts with thick patterns of long-distance migration and international trade. Velocity indicates the speed at which ideas, goods, information, capital and people are globally diffused. These diffusions are contingent upon available infrastructures of worldwide transport and communication. One can also measure the impact of distant events, decisions or activities upon local circumstances. Examples of high impact include colonization, world war, and world depression (pp. 16-21). These spatio-temporal processes do not constitute a teleology of global integration. Rather, the structure and dynamics of globalization are shaped by complex historical contingencies. There is much about the future of globalization that cannot be predicted. Certainly, it can be reliably stated that globalization is a multi-faceted phenomenon with economic, political, cultural, military, and environ- 
mental logics of development. These logics are variously interlinked, but the causal form and empirical content of such interlinkages are contestable over time. It should also be noted that the reach and density of global interconnectedness necessarily embody the exercise of structural power. This may take the form of exploitation, immiseration, colonization, military conquest, slavery (and related tribute systems). Under these circumstances, the historical experiences of globalization are diverse, disparate, and conflictual.

The preceding insights about globalization shape our understandings of global capitalism. However, the terms are not synonymous. At different historical conjunctures global capitalism has confronted worldwide networks of opposition. Examples include anti-colonial nationalism, international socialism, Third-World guerilla movements, radical ecology coalitions, rural farmer networks, and indigenous rights movements. With varying degrees of success, these organizational forms have projected anti-capitalist principles of globalization. Such principles are now expressed in a specifically self-conscious way. Contemporary formulations such as 'anticorporate movements', 'World Social Forum', and 'globalization from below' indicate that capitalism does not monopolize the global imaginary. Meanwhile, global capitalism adopts the mantle of globalization to position all opposition groups as out of place and out of time (e.g. as reactive protestors, parochial interests, or Luddites).

2. In making this argument, Hongladarom refers to Sandbothe (1999).

\section{References}

Aglietta, M. (1999) 'Capitalism at the Turn of the Century: Regulation Theory and the Challenge of Social Change', New Left Review 232: 41-90.

Altvater, E. (1998) 'Theoretical Deliberations on Time and Space in Post-Socialist Transformation', Regional Studies 32(7): 491-506.

Bauman, Z. (2000) 'Time and Space Reunited', Time \& Society 9(2/3): 171-85.

Beeson, M. (1998) 'From Hegemons to Hedge Funds: States, Markets, and the Reconfiguration of the International Economy', paper presented to the Australian and New Zealand Political Science Association Conference, Christchurch, 27-30 September.

Benoit, B. (2001) 'Siemens Discovers the Downside of Shareholder Capitalism', Financial Times, 18 October.

Blackburn, R. (2002) Banking on Death. London: Verso.

Castells, M. (1996) The Rise of the Network Society. Oxford: Blackwell.

Castells, M. (1997) The Power of Identity. Oxford: Blackwell.

Castells, M. (1998) The End of Millennium. Oxford: Blackwell.

Cetina, K. and Bruegger, U. (2002) 'Traders' Engagement with Markets', Theory, Culture and Society 19(5/6): 161-85.

Dyer-Witheford, M. (1999) Cyber-Marx: Cycles and Circuits of Struggle in High-technology Capitalism. Urbana, IL: University of Illinois Press.

Gandy, A. and Chapman, G. S. (1997) Information and Financial Services. Chicago: Fitzroy Dearborn.

Germain, R. (1997) The International Organization of Credit: States and Global Finance in the World Economy. Cambridge: Cambridge University Press.

Harvey, D. (1999) The Limits to Capital. London: Verso. 
Hassan, R. (2003) 'Network Time and the New Knowledge Epoch', Time \& Society 12(2/3): 225-41.

Held, D., McGrew, A., Goldblatt, D. and Perraton, J (1999) Global Transformations. Cambridge: Polity.

Hongladarom, S. (2002) 'The Web of Time and the Dilemma of Globalisation', The Information Society 18(4): 241-9.

Hope, W. (1998) 'Conceptualising Media-Economy Dynamics: Finance Capital, Television News and Electoral Democracy in New Zealand', paper presented to IAMCR Conference, University of Strathclyde, Glasgow, 26-30 July.

Hopper, K. (1997) 'Homelessness, Severe Mental Illness and the Institutional Circuit, Psychiatric Services 48: 659-65.

Lepper, J. (1996) 'International Finance and the Demise of Social Democracy', paper presented to the 'Democratic State, Individuals and Communities' Conference, University of Auckland, July.

Leyshon, A. (2000) 'Money and Finance', in E. Sheppard and T. Barnes (eds) A Companion to Economic Geography, pp. 432-50. Oxford: Blackwell.

McKenna, R. (1997) Real Time: Preparing for the Age of the Never Satisfied Customer. Boston: Harvard Business School Press.

Martin, R. (1994) 'Stateless Monies, Global Financial Integration and National Economic Autonomy: The End of Geography?', in S. Corbridge, R. Martin and N. Thrift (eds) Money, Power and Space, pp. 253-78. Oxford: Blackwell.

Marx, K. (1970) Capital: Volume I. London: Lawrence and Wishart.

Palmer, M. and Boyd-Barrett, O, (1998) 'Global Financial News', in O. Boyd-Barrett and T. Rantanen (eds) The Globalisation of News, pp. 61-78. London: SAGE Publications.

Ranadive, V. (1999) The Power of Now: How Winning Companies Sense and Respond to Change Using Real-time Technology. New York: McGraw Hill.

Sandbothe, M. (1999) 'Media Temporalities on the Internet: Philosophies of Time and Media', AI and Society 13(4): 421-34.

Sardar, Z. (1999) 'Dissenting Futures and Dissent in the Future', Futures 31(2): 139-46.

Siegele, L. (2002) 'How About Now? A Survey of the Real Time Economy', Economist, 2-8 February.

Singh, K. (2000) Taming Global Financial Flows. London: Zed Books.

Soederberg, S. (2001) 'The New International Financial Architecture: Imposed Leadership and Emerging Markets', in L. Panitch and C. Leys (eds) Socialist Register 2002, pp. 175-92. London: Merlin Press.

Tapscott, D. (1996) The Digital Economy. New York: McGraw-Hill.

Thompson, J. (1994) Ideology and Modern Culture. Cambridge: Polity.

Thrift, N. (1996) 'New Urban Eras and Old Technological Fears: Reconfiguring the Goodwill of Electronic Things', Urban Studies 33(8): 1463-93.

United Nations (2002) Least Developed Countries Report: Escaping the Poverty Trap. Available at: unctad.org/en/pub/psildc02.en.htm

Wark, M, (1994) Virtual Geography: Living with Global Media Events. Bloomington, IN: Indiana University Press.

Wolch, J. and DeVerteuil, G. (2001) 'New Landscapes of Urban Poverty Management', in J. May and N. Thrift (eds) Timespace Geographies of Temporality, pp. 149-68. London: Routledge. 
WAYNE HOPE is Associate Professor of Communication Studies at the Auckland University of Technology, New Zealand. His areas of research include public-sphere analysis, political economy of communication, sport-media relationships and globalization. He has published on these themes internationally and in the context of recent New Zealand history. He is at present writing a book on temporality and global capitalism. ADDRESS: School of Communication Studies, Auckland University of Technology, Private Bag 92006, Auckland 1020, New Zealand.

[email: wayne. hope@aut.ac.nz] 